\title{
Evaluation of Meropenem Utilization in Intensive Care Unit in Sudan
}

Osama M Sanhoury ${ }^{1}$ and Ahmed S Eldalo ${ }^{2 *}$

${ }^{1}$ Clinical Pharmacy, College of Pharmacy, Omdurman Islamic University, Sudan

${ }^{2}$ Clinical Pharmacology, College of Pharmacy, Taif University, Saudi Arabia

\begin{abstract}
Background: Antimicrobial agents are one of the frequently utilized drug classes in anIntensive Care Unit setting (ICU).

Objective: was to evaluate the meropenem utilization among Sudanese patients in the ICU in military hospital.

Method: A retrospective study was carried out in the ICU in military hospital during the period from September 2014 to February 2015.A well designed pretested questionnaire was used to collect the data. The collected data was analyzed using SPSS software version 17.

Results: A total of 135 patients' files were encountered. The results showed that, no culture was done for any patient before meropenem used. Overall $80 \%$ of meropenem was prescribed empirically, Out of the patients who's having meropenem, $7.41 \%$ were diagnosed pneumonias and $12.59 \%$ septicemia. Creatinine clearance was ranged from 50 to $137 \mathrm{ml} / \mathrm{min}$ in a total $40.8 \%$ of patients used meropenem, so they didn't need dose adjustment, while $59.2 \%$ of them needed dose adjustment since their creatinine clearance was range from 50 to $10 \mathrm{ml} / \mathrm{min}$. The therapeutic response was high $65.2 \%$ among the patients who using meropenem, while only $14.8 \%$ of them were not cured by this antibiotic. The dose was $0.5-1$ gm meropenem twelve hourly for most of patients.

Conclusion: Meropenem use in ICU appears to be inconsistent with evidence based assessment criteria. The most evident inappropriateness was observed in empirical therapy. The study also detected other potential problematic areas where concordance with standard guidelines is yet to be achieved. Continuous medical education, functional drug and therapeutic committees and regular drug utilization evaluation programs could help in accomplishing the milestone of rational medication use.
\end{abstract}

\section{Introduction}

Patients admitted to the Intensive care unit (ICU) are seriously ill and often suffer from chronic critical illnesses. These patients receive multiple medications from a variety of pharmacological classes due to life threatening illnesses. They are a unique group of population with diverse disease processes, existing or impending multi organ failure and potentially altered pharmacokinetic and pharmacodynamics characteristics onto which pharmacotherapy is added [1]. Drug therapy in critically ill is therefore complicated. The judicious use of these medications can be lifesaving. The routine use of conventional drug dosage regimens may expose a substantial portion of ICU patients to drug related problems such as treatment failure, drug interactions and high risk of adverse drug reactions. Careful titration of dosage regimens becomes imperative to ensure the ideal treatment outcome [2]. Antimicrobial agents are one of the frequently utilized drug classes in an ICU setting. Patients with critical illnesses are at higher risk of developing nosocomial infections and antibiotics are the most powerful and useful tools to manage these infections

Extensive and indiscriminate use of antimicrobial agents has been documented in ICUs in previous published reports. [3, 4]. The widespread use of broad-spectrum antibiotics has led to the emergence of several resistant strains of microbes. These contribute significantly towards rise in the escalating health care costs and patient morbidity and mortality $[3,4]$. Therefore, monitoring and evaluation of prescribing patterns of antimicrobial agents are one of the recommended strategies to contain and control resistance also to improve the prescribing practices. Drug utilization study is a component of medical audit that does monitoring and evaluation of the drug prescribing patterns and suggests necessary modifications in prescribing practices to achieve rational therapeutic practice as well as cost effective health care [5].
The inappropriate and unnecessary use of antibiotics is a common practice in health care setting $[6,7]$. It has been observed that irrational utilization of antibiotics lead to an escalation in the morbidity and mortality rate in community, healthcare cost and development of resistance against antibiotics [8,9]. Appropriate use of antibiotics could be promoted by use of an antibiotic stewardship program like drug utilization evaluation (DUE) with an aim of maximizing the therapeutic response while limiting the unintended side effects [10]. DUE is ongoing, systematic criteria- based evaluation of drug use that helps to ensure that medicines are used appropriately at an individual patient level [11]. The overall objective of DUE is to promote rational medication use. Antibiotics are one of the most common drugs prescribed in hospitals today. The use of antibiotic in hospitals has been a major concern in the last few decades for several reasons. It has been estimated that up to two third of all patients receive at least one antibiotic during hospitalization and the cost involved is therefore correspondingly high and up to $40 \%$ of a total hospital's drug expenditure may be devoted to the purchase of antibiotics [12]. From Administration point of view, it has contributed to the significant rise in hospital budget. Furthermore, from community perspective, inappropriate usage of antibiotic is considered a major reason for development of drug resistance against various pathogens. Similarly, patients have also suffered in the past due to increased side effects of antibiotics [13].

"Corresponding Author: Dr. Ahmed S Eldalo, Clinical Pharmacology, College of Pharmacy, Taif University, Saudi Arabia, E-mail: ahmed_dalo@hotmail.com

Citation: Sanhoury OM, Eldalo AS (2016) Evaluation of Meropenem Utilization in Intensive Care Unit in Sudan. Int J Clin Pharmacol Pharmacother 1: 106. doi: https://doi.org/10.15344/2456-3501/2016/106

Copyright: (c) 2016 Sanhoury et al. This is an open-access article distributed under the terms of the Creative Commons Attribution License, which permits unrestricted use, distribution, and reproduction in any medium, provided the original author and source are credited. 
Citation: Sanhoury OM,Eldalo AS (2016) Evaluation of Meropenem Utilization in Intensive Care Unit in Sudan. Int J Clin Pharmacol Pharmacother 1: 106. doi: https://doi.org/10.15344/2456-3501/2016/106

Page 2 of 4

Meropenem is a broad spectrum restricted antibiotic effective against Gram positive and Gram-negative organism and also against anaerobes. Various researchers have proved that meropenem is equally or more effective than conventional choices in conditions like febrile neutropenia and urinary tract infections, thereby increasing the frequency of prescriptions $[14,15]$. The objective of this study was to evaluate the meropenem utilization among patients in the ICU in military hospital, Khartoum Sudan.

\section{Materials and Methods}

Study design: A longitudinal observational retrospective study was carried out during the period from September 2014 to February 2015.

Study area and study population: All files of patients attending intensive care unit(ICU)in military hospital, Khartoum, Sudan during the study time and using meropenem as antibiotics were included.

Study instrument: A well-designed format was used to collect the data. The total sample size of 135 files was gathered. The data collected included two parts. The first part composed from questions about patient' age, weight, gender and any medications used other than meropenem. The second part constituted from questions about meropenem uses; dose, duration of uses, therapeutic outcome, and type of infection, results of bacterial culture test and creatinine clearance of patients (Table 1).

Study was approved by the committee of postgraduate studies, Faculty of Pharmacy, Omdurman University, and permission to access the data in the patient records anonymously was obtained from the Military Hospital administration.

Data analysis: The collected data was processed using Statistical Package for Social Sciences (SPSS) windows software version 17. Mean, frequencies as percentages were used to describe variables (Table 2).

\begin{tabular}{|l|l|l|l|}
\hline \multicolumn{2}{|l|}{ Characters } & Frequency & Percentage \\
\hline Gender & Male & 62 & $45.93 \%$ \\
\hline & Female & 73 & $54.07 \%$ \\
\hline Age & $<18$ & 10 & $7.41 \%$ \\
\hline & $18-30$ & 8 & $5.93 \%$ \\
\hline & $31-45$ & 10 & $7.41 \%$ \\
\hline & $46-60$ & 33 & $24.44 \%$ \\
\hline & $>60$ & 74 & $54.81 \%$ \\
\hline Weight & $<30$ & 10 & $7.41 \%$ \\
\hline & $30-60$ & 33 & $24.44 \%$ \\
\hline & $61-80$ & 65 & $30.95 \%$ \\
\hline & $>80$ & 27 & $12.86 \%$ \\
\hline
\end{tabular}

Table 1: Demographic characteristics of patients.

\section{Results}

A total 135 patients files who's used meropenem during hospitalization were analyzed. More than half 73 (54.0\%) of them were female. The majority $74(54.81 \%)$ of investigated patients were older than 60 years, Table1. Meropenem was prescribed for all patients without culture documented therapy or as prophylactic therapy. The majority of meropenem indications were as empirically $108(80 \%)$, followed by septicemia 17 (12.59\%), and pneumonia 10 (7.41\%) Figure 1.

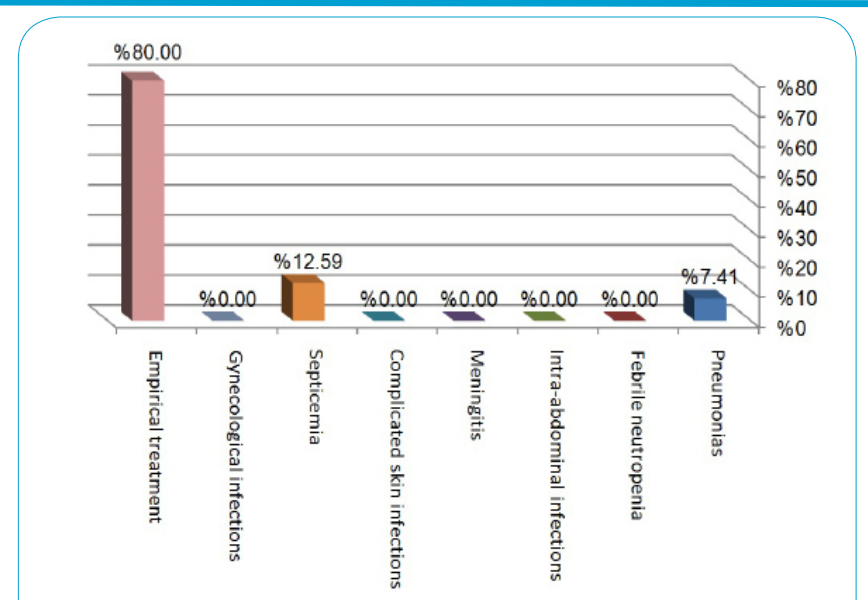

Figure 1: Clinical indications of meropenem.

Slightly more than half $70(51.85 \%)$ of meropenem prescribed was in combination with other antibiotics. The dominant combined antibiotics were ceftriaxone $1000 \mathrm{mg} 51$ (72.86\%), followed by ciprofloxacin $200 \mathrm{mg} 13$ (18.57\%), Figure 2.

Table 2 shows the dosage of meropenem used; 0.5-1 gm each 12 hours was the most common dosage used $1(60 \%)$, while $0.25-0.5 \mathrm{gm}$ twelve hourly was the least common dose 7 (5.19\%). The dominant duration days were 5-10 days $81(60 \%)$.

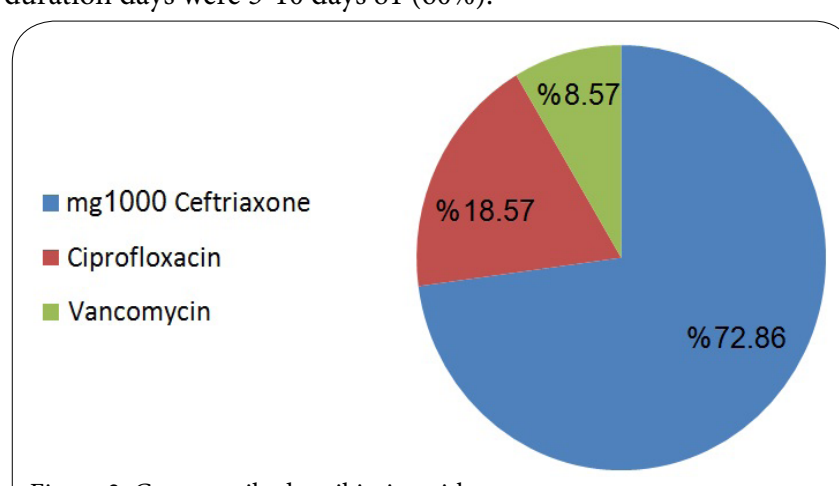

Figure 2: Co-prescribed antibiotics with meropenem.

\begin{tabular}{|l|l|l|l|l|}
\hline & Dose & $\begin{array}{l}\text { Dosing } \\
\text { frequency }\end{array}$ & Frequency & $\begin{array}{l}\text { Percentage } \\
(\%)\end{array}$ \\
\hline Dosage & 0.5 -1gm & $8 \mathrm{hr}$ & 34 & 25.19 \\
\hline & $0.5-1 \mathrm{gm}$ & $12 \mathrm{hr}$ & 81 & 60.00 \\
\hline & $0.25-0.5$ & $12 \mathrm{hr}$ & 7 & 5.19 \\
\hline $\begin{array}{l}\text { Duration of } \\
\text { therapy }\end{array}$ & $\begin{array}{l}\text { Less than } 5 \\
\text { days }\end{array}$ & $24 \mathrm{hrs}$ & 13 & 9.63 \\
\hline & $5-10$ days & & 10 & 7.41 \\
\hline & $\begin{array}{l}\text { More than } 10 \\
\text { days }\end{array}$ & & 41 & 60 \\
\hline Total & & & 135 & 32.59 \\
\hline
\end{tabular}

Table 2: Dosage and duration of therapy.

One fifth of patients received meropenem were died, while 88 $(65.2 \%)$ of them were well controlled after using this atibiotic, Figure 3.

Figure 4 shows the creatinine clearance among the patients received meropenem. A total 55 (40.7\%)of patients were normal creatinine clearance level, so they didn't need dose adjustment, while 40 (29.6\%)

Int J Clin Pharmacol Pharmacother ISSN: 2456-3501

IJCPP, an open access journal Volume 1. 2016. 106 
Citation: Sanhoury OM,Eldalo AS (2016) Evaluation of Meropenem Utilization in Intensive Care Unit in Sudan. Int J Clin Pharmacol Pharmacother 1: 106. doi: https://doi.org/10.15344/2456-3501/2016/106

Page 3 of 4

out of the patients had mild renal failure with creatinine clearance level between $26-50 \mathrm{ml} / \mathrm{min}$ so they need dose adjustment, and 20 (14.8\%)of them suffered from severe renal failure, since their creatinine clearance level was less than $10 \mathrm{ml} / \mathrm{min}$.

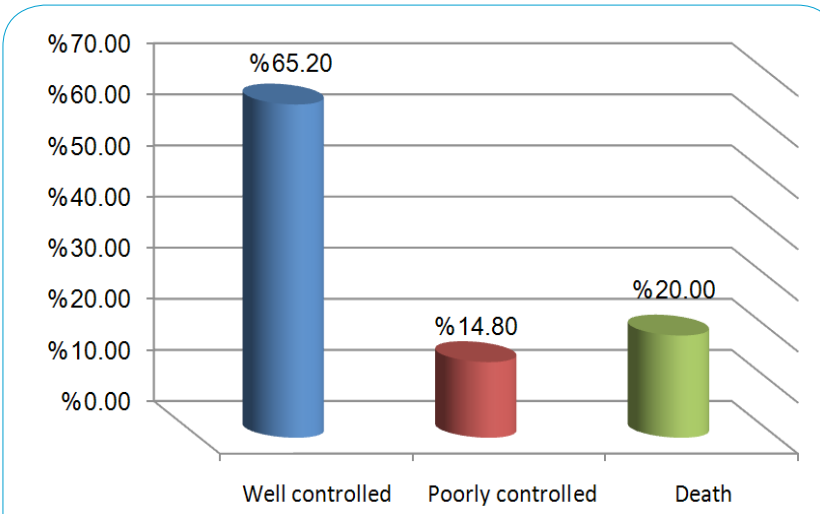

Figure 3: Clinical outcome after meropenem usage.

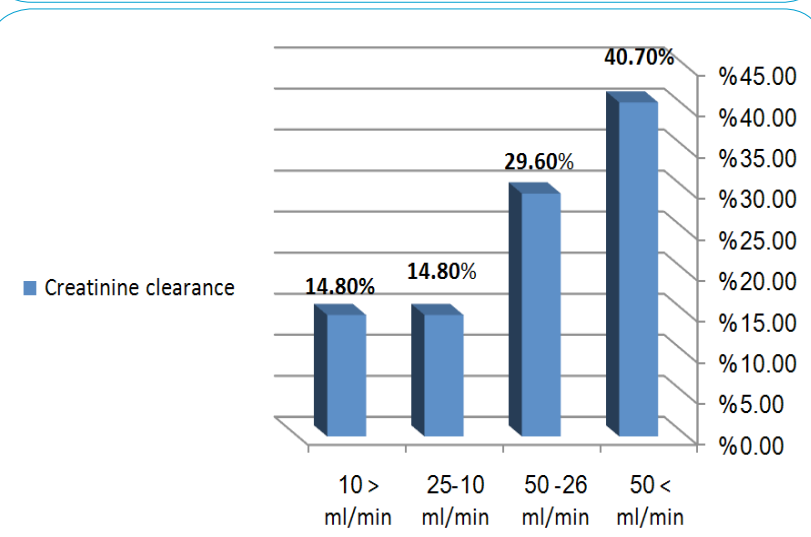

Figure 4: Creatinine clearance among the patients received meropenem.

\section{Discussion}

Meropenem is an antibiotic that is often used for empirical treatment of infections in critically ill patients with acute kidney injury. It has clinically insignificant protein binding (2 to 3\%) [16].

Proper educational, financial and regulatory programs directed towards health care professionals must be organized to promote rational use of meropenem. In addition provision of standard treatment guidelines, accompanied with onsite training and supervision may be helpful in guiding physicians in the appropriate use of meropenem in particular and antimicrobial in general.

Meropenem use evaluation in this study appears to be inconsistent with evidence based assessment criteria. The most evident inappropriateness was observed when meropenem was used as an empirical therapy. Physicians were used this antibiotic empirically for patients admitted to the ICU without determination the exact infection. They might think that all patients admitted to ICU are in a critical situation and with a high suspected infection. The study also detected other potential problematic areas where concordance with standard guidelines is yet to be achieved. The direct correlation between occurrence of side effects and declining renal function suggests the use of therapeutic drug monitoring in routine practice especially in renal compromised patients. Continuous medical education, functional drug and therapeutic committees and regular drug utilization evaluation programs could help in accomplishing the milestone of rational medication use. Efforts of individuals may not change the practice altogether, but it could influence on the numerous negative aspects of antibiotic usage in healthcare practice.

The clinical setting in the medical ICU warrants the use of drugs from various drug classes [17]. Rational prescription of drugs is essential for better patient care. The firststep in any intervention programme to improve drug utilization is to assess the extent of existing problem in prescribing [18]. As far as we know this is the first study was conducted in Sudan to evaluate drug utilization meropenem in ICU patients in military hospital.

The results of this study revealed that the majority of patients received meropenem were above 60 years old. Also $29.6 \%$ of them suffered from moderate to severe renal failure. This is probably for an excellent safety profile of meropenem in elderly and renally impaired patients which reported by Cunha 1998 [19].

In the current study overall meropenem was prescribed without culture; which means that the drug was used depending on prescribers' experience or on the basis of clinical decision, but not on culture based. This was in agree with a study conducted to evaluate the use of carbapenem in a French University hospital by Jary et al., which found $60 \%$ of meropenem was prescribed empirically [20].

The high therapeutic outcomes reported in this study was constant with a results reported by Cohen et al., which found that the majority of patients treated with meropenem met the therapeutic success [21].

In this study vancomycin was combined with meropenem in $8.57 \%$ of prescriptions, which conform with a suggestion by Stan, 2009 that; a combination of a $\beta$-lactam antibiotic with vancomycin may provide benefits in a therapy for serious MRSA infection [22].

\section{Conclusion}

Meropenem use evaluation in this study appears to be inconsistent with evidence based assessment criteria. The most evident inappropriateness was observed when meropenem was used as an empirical therapy. The study also detected other potential problematic areas where concordance with standard guidelines is not yet be achieved. Continuous medical education, functional drug and therapeutic committees and regular drug utilization evaluation programs could help in accomplishing the milestone of rational medication use. Also use of procalcitonin (PCT) to improve diagnosis of bacterial infections and to guide antibiotic therapy in infected patients in intensive care unit, which have benefits to guide decisions about initiation and / or discontinuation of antibiotic therapy.

\section{References}

1. Smythe MA, Melendy S, Jahns B, Dmuchowski C (1993) An exploratory analysis of medication utilization in a medical intensive care unit. Crit Care Med 21: 1319-1323.

2. Townsend PL, Reynolds JR, Zaske DE (1999) Applied Pharmacokinetics in the Intensive Care Unit. In, Irwin RS, CerraFB, Rippe JM (ed). Irwin and Rippe's Intensive Care Medicine. 4th ed. Lippincott-Raven Publishers 1413.

3. Niederman MS (2003) Appropriate use of antimicrobial agents: challenges and strategies for improvement. Crit Care Med 31: 608-616.

4. Pulcini C, Pradier C, Samat-Long C, Hyvernat H, Bernardin G, et al. (2006) Factors associated with adherence to infectious diseases advice in two intensive care units. J Antimicrob Chemother 57: 546-550. 
Citation: Sanhoury OM,Eldalo AS (2016) Evaluation of Meropenem Utilization in Intensive Care Unit in Sudan. Int J Clin Pharmacol Pharmacother 1: 106. doi: https://doi.org/10.15344/2456-3501/2016/106

5. Srishyla MV, Krishnamurthy M, Nagarani MA, Mary CSr, Andrade C, et al. (1994) Prescription audit in an Indian hospital setting using the DDD (Defined Daily Dose) concept. Indian J Pharmacol 26: 23-28.

6. Shahrazad M, Alireza H, Hassan T, Gholami K, Javadi MR (2013) Carbapenem Utilization in Critically III Patients. J Pharmceut Care 1: 141144.

7. Hersh AL, Shapiro DJ, Pavia AT, Shah SS (2011) Antibiotic prescribing in ambulatory pediatrics in the United States. Pediatrics 128: 1053-1061.

8. French GL (2005) Clinical impact and relevance of antibiotic resistance. Adv Drug Deliv Rev 57: 1514-1527.

9. Monroe S, Polk R (2000) Antimicrobial use and bacterial resistance. Curr Opin Microbiol 3: 496-501.

10. Dellit TH, Owens RC, McGowan JE, Gerding DN, Weinstein RA, et al. (2007) Infectious Diseases Society of America and the Society for Healthcare Epidemiology of America guidelines for developing an institutional program to enhance antimicrobial stewardship. Clin Infect Dis 44: 159- 177.

11. WHO (2002) Promoting rational drug use of medicines; core components World Health Organization 1-6.

12. Mauldin PD, Salgado CD, Hansen IS, Durup DT, Bosso JA (2010) Attributable hospital cost and length of stay associated with health careassociated infections caused by antibiotic-resistant gram-negative bacteria. Antimicrob Agents Chemo 54: 109- 115.

13. Kleinke JD (2001) The price of progress: prescription drugs in the health care market. Health Aff (Millwood) 20: 43-60.

14. Gupta N, Sharma D, Garg S, hargava V (1997) Auditing of prescriptions to study utilization of antimicrobials in a tertiary hospital. Indian J Pharmacol 29: 411.

15. Klastersky J, Paesmans M, Rubenstein EB, Boyer M, Elting L, et al. (2000) The Multinational Association for Supportive Care in Cancer risk index: A multinational scoring system for identifying low-risk febrile neutropenic cancer patients. J Clin Oncol 18: 3038-3051.

16. Hurst M, Lamb HM (2000) Meropenem: a review of its use in patients in intensive care. Drugs 59: 653-680.

17. Farooq JA, Ajaz M, Pandita KK, Rehana KMS, Yattoo GH, et al. (2013) Drug Utilization at SKIMS-A Tertiary Care Hospital. JK-Practitioner. 18: 3540.

18. John LJ, Devi P, John J, Guido S (2011) Drug Utilization Study of Antimicrobial Agents in Medical Intensive Care Unit of A Tertiary Care Hospital. Asian J Pharm Clin Res 4: 81-84.

19. Cunha BA (1998) Meropenem in elderly and renally impaired patients. Int J Antimicrob Agents 10: 107-117.

20. Jary F, Kaiser JD, Henon T, Leroy J, Patry I, et al. (2012) Appropriate use of carbapenems in the Besançon university hospital. Med Mal Infect 42 : 510-516.

21. Cohen-Wolkowiez M, Poindexter B, Bidegain M, Weitkamp JH, Schelonka $\mathrm{RL}$, et al. (2012) Safety and effectiveness of meropenem in infants with suspected or complicated intra-abdominal infections. Clin Infect Dis. 55: 1495-502.

22. Deresinski S (2009) Vancomycin in Combination with Other Antibiotics for the Treatment of Serious Methicillin-Resistant Staphylococcus aureusInfections. Clin Infect Dis 49: 1072-1079. 